\title{
Multispecies Probiotic Supplementation Favorably Affects Vascular Function and Reduces Arterial Stiffness in Obese Postmenopausal Women-A 12-Week Placebo-Controlled and Randomized Clinical Study
}

\author{
Monika Szulińska ${ }^{1}$, Igor Łoniewski ${ }^{2, *}$, Katarzyna Skrypnik ${ }^{3}{ }^{\circledR}$, Magdalena Sobieska ${ }^{4}(\mathbb{D}$, \\ Katarzyna Korybalska ${ }^{5}$, Joanna Suliburska ${ }^{3}{ }^{(D)}$ and Paweł Bogdański ${ }^{1}$ (D) \\ 1 Department of Treatment of Obesity, Metabolic Disorders and Clinical Dietetics, University of Medical \\ Sciences in Poznań, Szamarzewskiego Str. 84, 60-569 Poznań, Poland; mszulinska1@wp.pl (M.S.); \\ pawelbogdanski73@gmail.com (P.B.) \\ 2 Department of Biochemistry and Human Nutrition, Pomeranian Medical University in Szczecin, \\ Broniewskiego 24, 71-460 Szczecin, Poland \\ 3 Institute of Human Nutrition and Dietetics, Poznan University of Life Sciences, Wojska Polskiego St. 31, \\ 60-624 Poznań, Poland; katarzyna.skrypnik@gmail.com (K.S.); jsulibur@up.poznan.pl (J.S.) \\ 4 Department of Rheumatology and Rehabilitation, Poznan University of Medical Sciences, 28. Czerwca 1956r \\ 135/147, 61-55 Poznań, Poland; msobieska@ump.edu.pl \\ 5 Department of Pathophysiology, Poznan University of Medical Sciences, \\ Rokietnicka 8, 60-806 Poznan, Poland; koryb@ump.edu.pl \\ * Correspondence: sanprobi@sanprobi.pl; Tel.: +48-501-653-277
}

Received: 26 September 2018; Accepted: 29 October 2018; Published: 5 November 2018

check for updates

\begin{abstract}
Obesity in the postmenopausal period is associated with an increased risk of cardiovascular diseases in women. One of the key drivers of cardiovascular risk is endothelial dysfunction; thus, this is also a crucial point for studies on new therapeutic methods of cardioprotective properties. The aim of the current study was to evaluate the effect of two doses of multispecies probiotic Ecologic ${ }^{\circledR}$ Barrier supplement on functional (primary endpoint) and biochemical parameters (secondary endpoint) of endothelial dysfunction in obese postmenopausal women in a 12-week randomized, placebo-controlled clinical trial. A total of 81 obese Caucasian women participated in the trial. The subjects were randomly assigned to three groups that received a placebo, a low dose (LD) $\left(2.5 \times 10^{9}\right.$ colony forming units (CFU) per day), or a high dose (HD) $\left(1 \times 10^{10} \mathrm{CFU}\right.$ per day) of lyophilisate powder containing live multispecies probiotic bacteria. The probiotic supplement was administered each day for 12 weeks in two equal portions. A high dose probiotic supplementation for 12 weeks decreased systolic blood pressure, vascular endothelial growth factor, pulse wave analysis systolic pressure, pulse wave analysis pulse pressure, pulse wave analysis augmentation index, pulse wave velocity, interleukin-6, tumor necrosis factor alpha, and thrombomodulin. Low doses of probiotic supplementation decreased the systolic blood pressure and interleukin- 6 levels. The mean changes in the estimated parameters, compared among the three groups, revealed significant differences in the vascular endothelial growth factor, the pulse wave analysis systolic pressure, the pulse wave analysis augmentation index, the pulse wave velocity, the tumor necrosis factor alpha, and thrombomodulin. The post hoc tests showed significant differences for all parameters between HD and the placebo group, and HD and LD (besides pulse wave analysis augmentation index). We show for the first time that supplementation with multispecies probiotic Ecologic ${ }^{\circledR}$ Barrier favorably modifies both functional and biochemical markers of vascular dysfunction in obese postmenopausal women.
\end{abstract}

Keywords: probiotics; endothelium; arterial stiffness; postmenopausal women 


\section{Introduction}

Increased scientific interest in the endothelium has risen from the fact that beyond any doubt, an unfavorable modification of endothelial cells, leading to endothelial dysfunction, is closely associated with an increased risk for cardiovascular diseases [1]. Changes associated with the deterioration of endothelial function are responsible for vascular remodeling and the activation of inflammatory and thrombotic processes, and they are early markers of atherosclerosis development [2]. Detailed knowledge about pathologic mechanisms leading to endothelial dysfunction in obesity is a crucial point for studies on new therapeutic methods of cardioprotective properties.

Obesity, a global epidemic affecting 700 million people worldwide, disrupts endothelial function. In obese patients, enhanced vasoconstriction is observed, mainly due to endothelincyclooxygenase hyperactivity [3], and angiotensin-1 receptor hyper-production occurs, which could be the basis of hypertension in these individuals [4]. It has been widely documented that visceral obesity significantly aggravates endothelial dysfunction $[5,6]$. Obesity promotes a low-intensity inflammatory state, leading to the over-secretion of inflammation mediators such as the tumor necrosis factor (TNF) and interleukin-6 (IL-6), which significantly affect endothelium function [7] and homeostasis. The regulation of angiogenesis by endothelial cells is carried out by the expression of receptor proteins on their surface, and the synthesis of numerous proangiogenic factors, among which the most important seems to be the vascular endothelial growth factor (VEGF), as well as anti-angiogenesis factors (protease inhibitors: tissue inhibitors of metalloproteinases (TIMPs), thrombospondin 1 and 2) [8]. These processes are disturbed in obesity. The proangiogenic activity of VEGF is multidirectional, and it includes chemotactic and mitogenic effects, an increase in the migration of endothelial cells and their progenitor cells, and activity-degrading basement membranes, which lead to an increased blood vessel permeability [9]. Simultaneously, the endothelium influences fibrinolysis-producing tissue plasminogen activator and plasminogen activator inhibitor 1 , and can be a source of the von Willebrand factor (vWF) and thrombomodulin (TM) - important coagulation factors [10-12]. TM interacts with the thrombin that is present in the plasma and contributes to changes in its conformation. In obesity, due to the ability of TM to be cleaved by inflammatory agents, it can be considered a marker of endothelial cell damage [13]. Endothelial cells are a source of vWF and play an important role in the process of platelet adhesion and aggregation [14].

An understanding of the importance of ED in the pathology of cardiovascular diseases has led to the development of methods to measure the grade of this dysfunction. Commonly used methods of ED examination are biochemical measurements and non-invasive functional tests. The basic method of endothelium examination based on applanation tonometry allows for the evaluation of pulse wave velocity (PWV). The value of the PWV index is inversely proportional to the stiffness of the arterial wall. The predictive value of this method grows rapidly $[15,16]$.

An understanding of the importance of endothelial dysfunction in the pathology of cardiovascular diseases allows for the capabilities of endothelial function to be investigated and modified. Non-pharmacological interventions in endothelial function are widely available, cheap, devoid of side effects, and attractive. An increasing amount of scientific proof confirms its favorable cardioprotective impact; thus, further studies on this topic are needful. In recent years, the field of non-pharmacological interventions has become of special interest for our research team [17-21]. Probiotics are considered to be alternative supplements that can modulate the composition and function of gut microbiota. An improper diet and a sedentary lifestyle lead to obesity, which has effects on chronic inflammatory responses. Sub-clinical inflammation is a reason for dysbiosis and the increased permeability of the intestinal wall. Due to this phenomenon, bacterial lipopolysaccharides penetrate into the bloodstream, and cause an increased production of trimethylamine N-oxide (TMAO) and decreased TAS (total antioxidant status). The entirety of these processes leads to endothelial dysfunction [22]. The strain-specific capacities of bacteria in the multispecies probiotic Eccologic ${ }^{\circledR}$ Barrier that are designed to improve the epithelial barrier have been recently investigated [23]. The administration of the Ecologic ${ }^{\circledR}$ Barrier was also shown to improve insulin resistance and reduced abdominal 
adiposity in type 2 diabetes mellitus (T2DM) patients [24]. In our recently published 12-week randomized, placebo-controlled, double-blind study, we showed that supplementation with Ecologic ${ }^{\circledR}$ Barrier in obese postmenopausal women favorably influences cardiometabolic parameters and gut permeability [25]. Our results suggest that these products can be effective in the prevention and treatment of cardiovascular diseases in obese postmenopausal women. Although the multiple potential effects of probiotics have been studied, no data regarding the influence of multispecies probiotics on endothelial function in obese postmenopausal women are available so far. Women of postmenopausal age develop an increased risk of developing cardiovascular diseases due to multiple hormonal changes. Our previous results obtained in obese individuals led us to investigate the hypothesis concerning the positive effect of supplementation with the multispecies probiotic Ecologic ${ }^{\circledR}$ Barrier on further endothelium-related, cardiovascular risk factors in female patients with obesity.

The aim of the study was to evaluate the effects of different doses of supplemented multispecies probiotics on the functional (primary endpoint) and biochemical parameters (secondary endpoint) of endothelial and vascular dysfunction in obese postmenopausal women in a 12-week randomized, placebo-controlled clinical trial.

\section{Methods}

The study was designed as a 12-week single-center (Department of Education and Treatment of Obesity and Metabolic Disorders University of Medical Sciences in Poznań, Poland), randomized, double-blind, placebo-controlled clinical trial. The protocol was registered at the US National Institute of Health (ClinicalTrails.gov Identifier: NCT03100162). Ethical approval was obtained from the Bioethical Committee of Poznan University of Medical Sciences (No. 871/2015) and written informed consent was obtained from all participants prior to inclusion. The study took place from 27 February 2016 to 31 December 2017.

\subsection{Subjects}

In the current study, the same participant sample was used, as in the study previously published by our group [25]. All patients were recruited from the outpatient department of the University Hospital, Poznań, Poland. A total of 110 obese postmenopausal women were initially invited to participate. The inclusion criteria were as follows: (1) women aged 45-70 years; (2) $\geq 6$ months since last menstruation; (3) a body mass index (BMI) of $30-45 \mathrm{~kg} / \mathrm{m}^{2}$; (4) abdominal obesity, that is, a waist circumference of $>80 \mathrm{~cm}$ (International Diabetes Federation 2005); (5) a content of body fat assessed by electrical bioimpedance that is $\geq 33 \%$; and (6) a stable body weight in the month prior to the trial (permissible deviation $\pm 1 \mathrm{~kg}$ ). Patients presenting any of the following exclusion criteria were excluded from the study: (1) secondary forms of obesity; (2) gastrointestinal diseases; (3) diabetes; (4) pharmacotherapy of hypertension or dyslipidemia in the three months prior to the trial; (5) history of use of any dietary supplements within three months before the study; (6) intake of antibiotics within one month before the study; (7) clinically significant acute inflammatory processes; (8) nicotine, alcohol, or drug abuse; (9) participation in weight-management studies or the use of medications known to alter food intake or body weight; (10) vegetarian dietary habits; (11) the use of pre- and probiotic-enriched products (for at least three weeks before the screening visit of the study), and products with a high content of dietary fiber or high quantities of fermented food ( $>400 \mathrm{~g} /$ day); and (12) hormonal replacement therapy. The occurrence of any of the above exclusion criteria during the trial resulted in the immediate cessation of participation in the study. Twenty-nine patients did not qualify for the study due to improper inclusion/exclusion criteria. Finally, 81 consecutive women diagnosed with obesity were eligible and gave informed consent. They were randomly assigned to either placebo or probiotic sachets that in a double-blinded manner. Finally, 71 participants (Placebo group, $n=24$; the low dose of the probiotic (LD) group, $n=24$, high dose of the probiotic (HD) group, $n=23$ ) completed the 12 -week intervention. No serious adverse reactions were reported following the consumption of multispecies probiotic supplements in postmenopausal women with obesity 
throughout the study. Furthermore, patients did not take any new medicines during the study. For a number of patients, a follow-up was not possible, and the reasons for this are outlined in the flowchart (Figure 1).

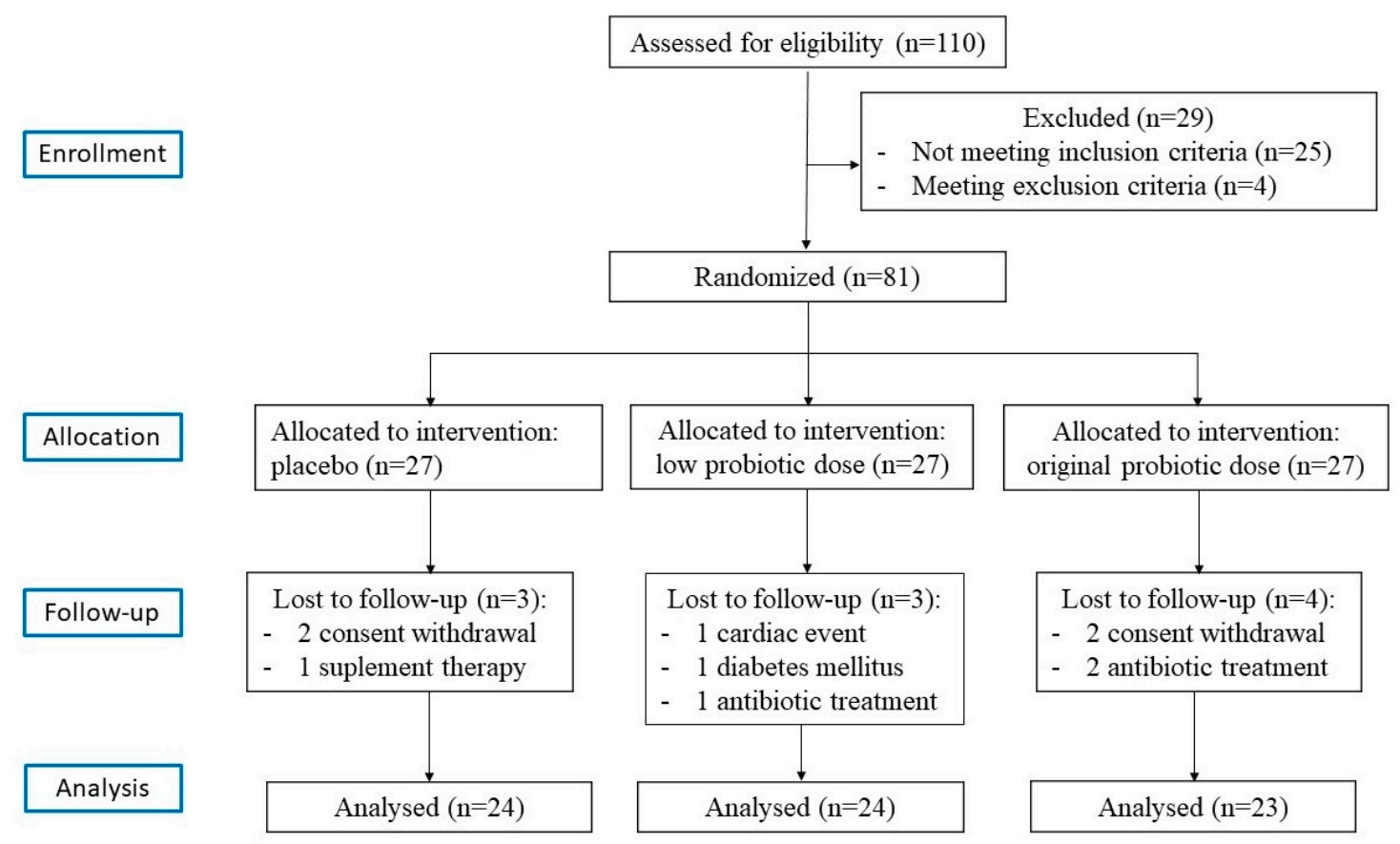

Figure 1. A flowchart of the study design.

\subsection{Probiotic Supplements and Allocation}

All eligible and consenting participants were given a unique code as an identifier. They were allocated (1:1:1) to receive either probiotics (high or low dose) or a placebo. The randomization scheme was computer-generated by Winclove using permuted blocks with a block size of 4 . It was impossible for the research personnel involved with the participants to adjust the randomization, or to discern which product the participants were receiving, ensuring true allocation concealment. The probiotic group received sachets containing $2 \mathrm{~g}$ of freeze-dried powder of the probiotic mixture Ecologic ${ }^{\circledR}$ Barrier (Winclove probiotics, Amsterdam, The Netherlands). The HD group received Ecologic ${ }^{\circledR}$ Barrier HD ( 2 g sachets, 2 sachets per day, $2.5 \times 10^{9}$ colony-forming units (CFU) per gram $=1 \times 10^{10}$ per day), whereas the LD group received Ecologic ${ }^{\circledR}$ Barrier LD ( 2 g sachets, 2 sachets per day, $0.625 \times 10^{9}$ $\mathrm{CFU} / \mathrm{g}=2.5 \times 10^{9}$ per day). The probiotic preparation contained the following bacterial strains: Bifidobacterium bifidum W23, Bifidobacterium lactis W51, Bifidobacterium lactis W52, Lactobacillus acidophilus W37, Lactobacillus brevis W63, Lactobacillus casei W56, Lactobacillus salivarius W24, Lactococcus lactis W19, and Lactococcus lactis W58 (a total cell count of $2.5 \times 10^{9} / \mathrm{g}$ ). All strains were present in approximately equal amounts, and the quality of the study batch was tested every three months to confirm the viability of the strains. With the application of new molecular identification techniques (including whole genome sequencing), the declaration of the bacterial strains for Ecologic ${ }^{\circledR}$ Barrier was updated from previous publications [23]. It has been confirmed that the probiotic formulation has always contained the nine mentioned strains, and it has not been changed in ratio or CFU count since it has been (commercially) available. The placebo group received the same sachets consisting of the carrier of the probiotic product, which was maize starch and maltodextrins. The placebo was indistinguishable in color, smell, and taste from the probiotic sachets. All participants were asked to consume two sachets per day (by dissolving the contents in a glass of water), once before breakfast and once before going to bed. Participants were asked to return every four weeks to surrender unused sachets and to 
be given fresh refills to monitor compliance. Participants were asked not to alter their routine physical activity or their usual diet. Participants were also asked to report any side effects.

\subsection{Anthropometric Measurement}

At the baseline and after 12 weeks of treatment, the anthropometric parameters were evaluated and all laboratory tests were performed for each group. All measurements were obtained after an overnight fast. The weight was measured to the nearest $0.1 \mathrm{~kg}$ and height was estimated to the nearest $0.5 \mathrm{~cm}$. The body mass index (BMI) was calculated as weight divided by height squared $\left(\mathrm{kg} / \mathrm{m}^{2}\right)$.

\subsection{Functional Parameters}

Blood pressure (BP) was measured using a brachial cuff (Omron Healthcare, Kyoto, Japan) on the right arm in a sitting position. The measurements were taken three times at 2-min intervals after a $10 \mathrm{~min}$ rest, and the average was used for analysis.

Both pulse wave velocity (PWV) and pulse wave analysis (PWA) measurements were then performed using the SphygmoCor Px (Atcor Medical Blood Pressure Analysis System, Sydney, Australia) in a temperature-controlled room, before making anthropometric measurements and blood collection, in the Department of Education and Treatment of Obesity and Metabolic Disorders University of Medical Sciences in Poznań, Poland. PWV was evaluated between the carotid and femoral artery, with the participant lying in the supine position. Pulse measurements were performed non-invasively using the SphygmoCor probe over the carotid and femoral artery, while an electrocardiogram (ECG) recording was performed simultaneously [26]. To ensure a stable, artifact-free ECG, the skin was properly prepared (the hair was removed at the electrode site and the skin was cleaned with an alcohol wipe). A minimum of $12 \mathrm{~s}$ of the signal (approximately 10 heartbeats) was recorded after a strong accurate and reproducible pulse wave signal had been obtained. The distance from the carotid to the femoral artery was measured directly between each artery location and the suprasternal notch, and the values were entered into the SphygmoCor software database. PWV was calculated by measuring the time delay between two characteristic timing points on two pressure waveforms that were at a known distance apart. The SphygmoCor method uses the foot of the waveform as an onset point for calculating the time differences between the R wave of the ECG, and the pulse waveforms at each site. The PWV was automatically calculated by the Atcor software as the carotid-femoral artery distance divided by the wave traveling time between the above two measuring sites. PWV measurements with a standard deviation of less than $10 \%$ were used for analysis [27].

The central aortic hemodynamic parameters, augmentation index (Alx), aortic pressure (AP), and pulse pressure (PP), were measured using the applanation tonometry of the radial artery, as previously described [28]. Two pressure peaks characterize the systolic part of the central waveform. The first peak results from the left cardiac ventricle ejection, and the second one results from the wave reflections from the periphery. The difference between these two peaks represents the degree of the central arterial pressure augmentation due to wave reflection. The AP is the absolute increase of the PP due to the reflected wave, and AI75 is the measure of the contribution of the wave reflection to the arterial pressure waveform. AI75 is expressed as a percentage of the PP. The amplitude and timing of the reflected wave ultimately depend on the stiffness of the small vessels and large arteries, representing a measurement of the systemic arterial stiffness $[26,28]$.

\subsection{Biochemical Parameters}

The serum level of high sensitivity (hs) TNF- $\alpha$ was measured using an enzyme immunoassay (DRG Instruments GmbH, Marburg, Germany). The sensitivity of the test was $0.7 \mathrm{pg} / \mathrm{mL}$. The concentration of hs Interleukin (IL)- 6 was determined in the serum samples with an immunoassay method (ELISA). For this purpose, an EIA-4640 kit, Interleukin 6 Human ELISA Kit (DRG Instruments $\mathrm{GmbH}$, Marburg, Germany) was used. The sensitivity of the test was $2.0 \mathrm{pg} / \mathrm{mL}$. 
The serum level of VEGF was measured using a quantitative immunoassay (R\&D Systems, Minneapolis, MN, USA). The serum thrombomodulin (TM) concentration was determined by an immunoenzymatic ELISA using the IMUBIND Thrombomodulin ELISA Kit (American Diagnostica Inc., Stamford, CT, USA). A commercially available ELISA kit (R\&D Systems, Minneapolis, MN, USA) was used for the determination of levels of the von Willebrand factor.

\subsection{In Vitro Assay}

Cell culture studies were performed using human umbilical vein endothelial cells HUVEC EA.hy926 line (kindly donated by Dr. C.J.S. Edgell, University of North Carolina, Chapel Hill, NC, USA) [29]. All cell culture reagents were from Sigma (St. Louis, MI, USA) and the cell culture plastics were from Nunc (Roskilde, Denmark). Cells were routinely maintained in Earle's buffered M199 culture medium supplemented with L-glutamine $(2 \mathrm{mM})$, penicillin $(100 \mathrm{U} / \mathrm{mL})$, streptomycin $(100 \mu \mathrm{g} / \mathrm{mL})$, hydrocortisone $(0.4 \mu \mathrm{g} / \mathrm{mL})$, and $10 \%(v / v)$ of foetal calf serum (Invitrogen, Karlsruhe, Germany). For the experiments, the cells were seeded into multi-well plates at a density of $4000 \mathrm{cells} / \mathrm{cm}^{2}$ and allowed to adhere for $24 \mathrm{~h}$. After that, the cells were rendered quiescent by serum deprivation for $24 \mathrm{~h}$ and exposed in triplicate to $20 \%(v / v)$ patients' serum (placebo, HD, LD groups) for the next $24 \mathrm{~h}$. Cells were then assessed for growth using the MTT (Methyl-Tetrazolium-Test) conversion assay [30], as previously described [31]. Briefly, following a 24-h exposure to medium supplemented with patients' serum, cells were incubated for $4 \mathrm{~h}$ at $37^{\circ} \mathrm{C}$ with $1.25 \mathrm{mg} / \mathrm{mL}$ MTT salt (3-(4,5-dimethylthiazol-2-yl) -2,5-diphenyl-tetrazolium bromide). The formazan product generated was dissolved with an acidic solution of $20 \%(w / v)$ sodium dodecyl sulfate and $50 \%(v / v) N, N$-dimethylformamide. The absorbance of the converted dye was recorded at $595 \mathrm{~nm}$. The data was expressed as a percentage of the control (cells maintained in a normal culture medium). The measurement was performed separately for each subject.

\subsection{Statistical Analysis}

The subjects' randomization codes were concealed until the statistical analysis. The data are shown as means \pm standard deviations (SDs). The normal distribution for each group was checked by the Shapiro-Wilk test. To examine the differences among groups, the Kruskal-Wallis test with a post-test (a multiple comparison test) or a one-way analysis of variance (ANOVA) test with a post-test (Tukey test) was used (if the data was normally distributed). To determine the differences between the effects of the treatment, the Wilcoxon test or the paired $t$-test was conducted (if the data was normally distributed). The standardized mean differences (Cohen's d) were used as a magnitude of the effect. Effect size thresholds of $0.2,0.5$, and 0.8 were used for small, medium, and large effects, respectively. Statistics were performed with the STATISTICA (data analysis software system), version 12 (StatSoft, Inc., Tulsa, OK, USA). A $p$ value of $<0.05$ was regarded as significant.

\section{Results}

The baseline characteristics of the studied population are shown in Table 1. There were no statistically significant differences in analyzed parameters among the HD, LD, and placebo groups at the baseline, except for VEGF (Table 1). At the baseline, the serum levels of VEGF were higher $(p<0.001)$ in the HD group in comparison to the placebo group. 
Table 1. The baseline characteristics of studied parameters in the high dose (HD), low dose (LD), and placebo groups.

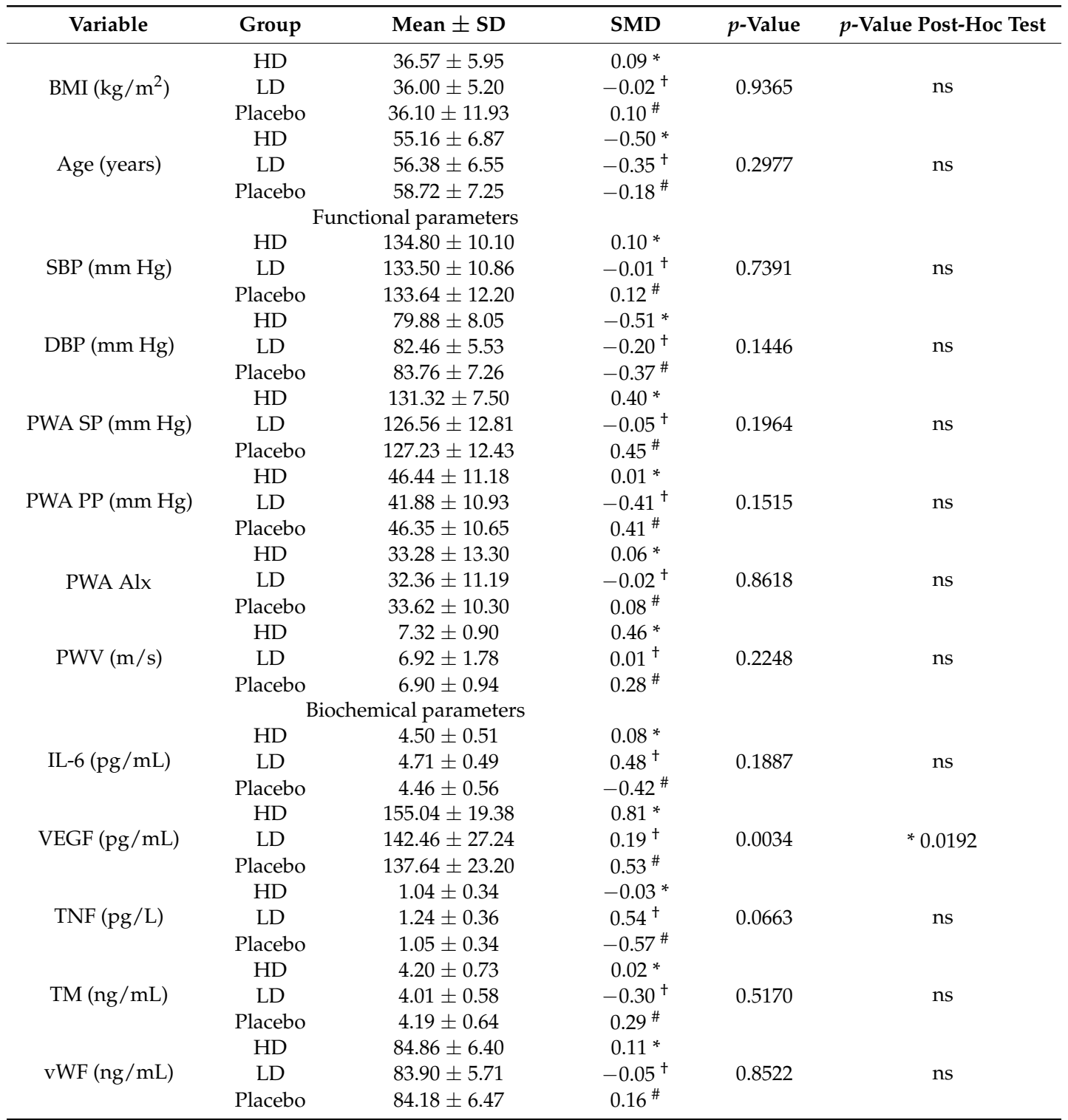

Data are the arithmetic mean \pm SD; SMD: standardized mean difference; ns: not significant; BMI: body mass index; DBP: diastolic blood pressure; Il-6: interleukin-6; PWA Alx: pulse wave analysis augmentation index; PWA PP: pulse wave analysis pulse pressure; PWA SP: pulse wave analysis systolic pressure; PWV: pulse wave velocity; SBP: systolic blood pressure; TM: thrombomodulin; TNF: tumor necrosis factor alpha; VEGF: vascular endothelial growth factor; vWF: von Willebrand factor. ${ }^{*} \mathrm{HD}$ : high dose of the probiotic group vs. placebo; ${ }^{\dagger} \mathrm{LD}$ : low dose of the probiotic group vs. placebo; ${ }^{\#} \mathrm{HD}$ vs. LD.

Significant changes in some evaluated parameters, as compared before and after 12 weeks of supplementation, were found in both the HD and LD probiotic supplemented groups, but not in the placebo group (Table 2, Figures 2 and 3). High doses of probiotic supplementation for 12 weeks decreased several parameters: SBP by $2.52 \%(p<0.0359$, SMD $=0.39)$, VEGF by $21.62 \%(p<0.0004$, SMD $=1.73)$, PWA SP by $7.29 \%(p<0.0004$, SMD $=1.01)$, PWA PP by $12.51 \%(p<0.0103$, SMD $=0.67)$, PWA Alx by $17.18 \%(p<0.0021, \mathrm{SMD}=0.58)$, PWV by $11.89 \%(p<0.0013$, SMD $=1.13)$, Il- 6 by $2 \%$ $(p<0.0173$, SMD $=0.15)$, TNF- $\alpha$ by $18.27 \%(p<0.0001$, SMD $=0.56)$, and TM by $10.24 \%(p<0.0006$, $\mathrm{SMD}=0.59)$. Low doses of probiotic supplementation decreased SBP by $1.96 \%(p<0.0498, \mathrm{SMD}=0.26)$ and Il- 6 by $4.46 \%(p<0.0396, \mathrm{SMD}=0.43)$. 


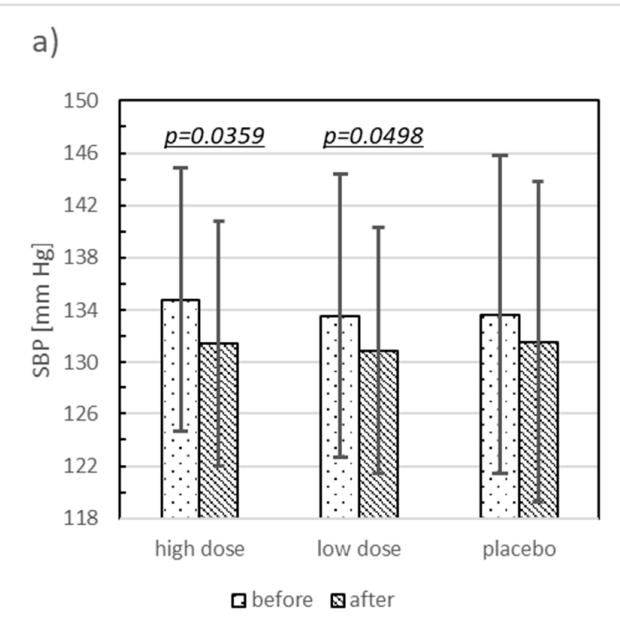

c)

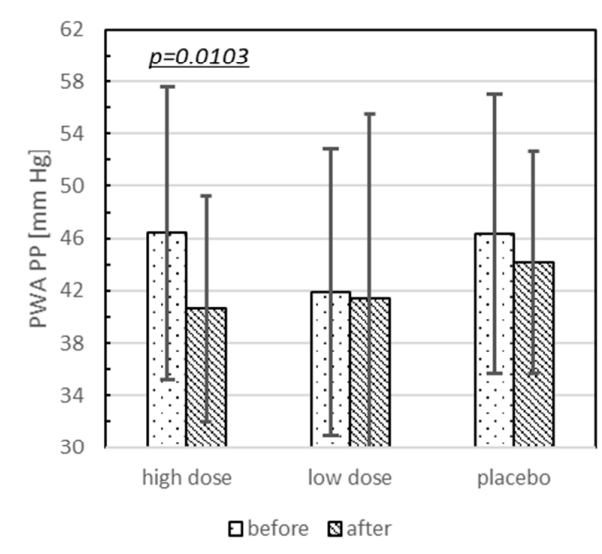

e)

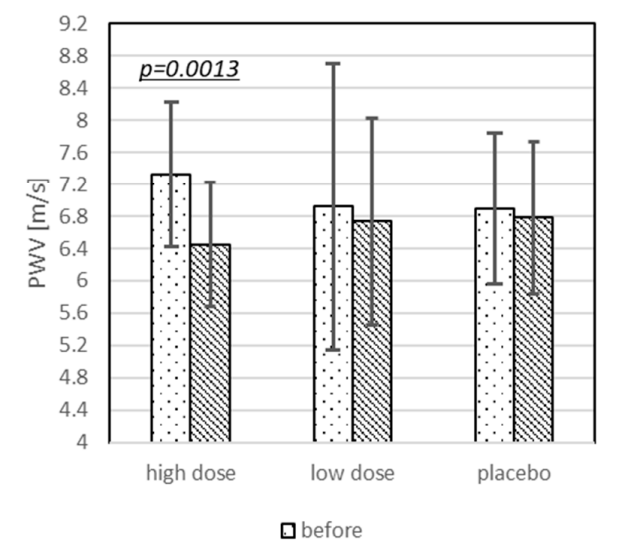

Figure 2. The comparison of the functional parameters in the high dose (HD), low dose (LD), and placebo groups at the beginning of the study and after three months of probiotic supplementation. Significant differences are highlighted showing the $p$-value. Data are the arithmetic mean \pm SD; (a) SBP: systolic blood pressure; (b) PWA SP: pulse wave analysis systolic pressure; (c) PWV: pulse wave velocity; (d) PWA Alx: pulse wave analysis augmentation index; (e) PVV: pulse wave velocity. b)

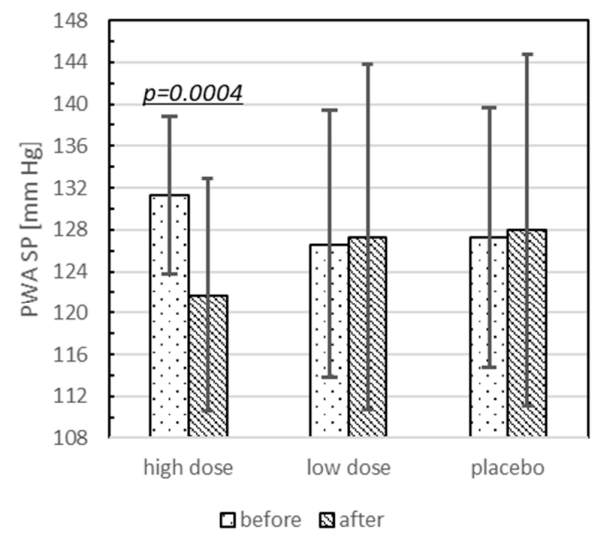

d)

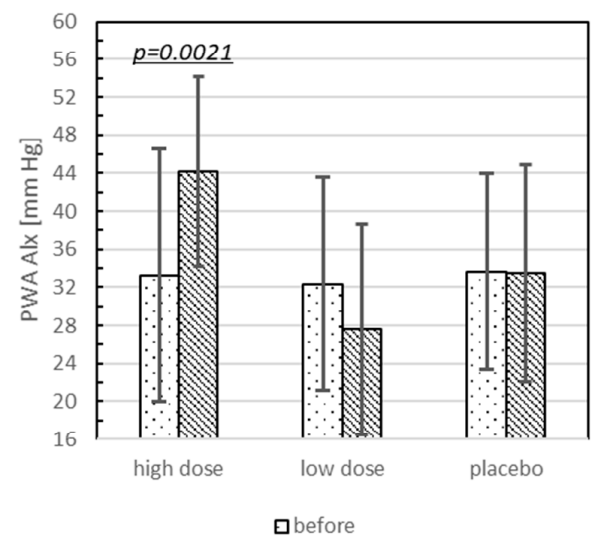




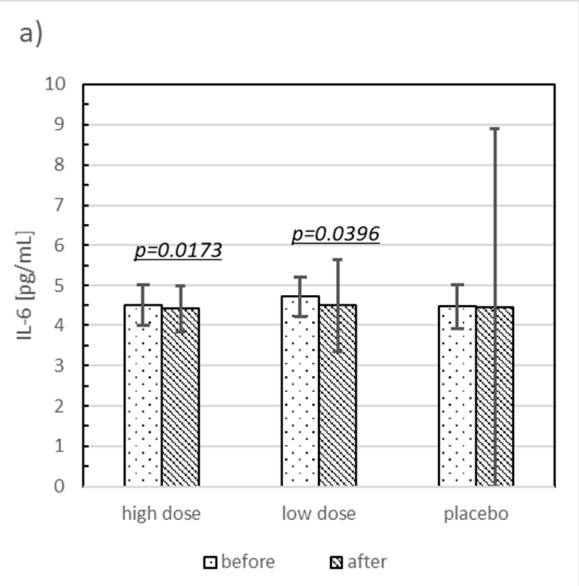

c)

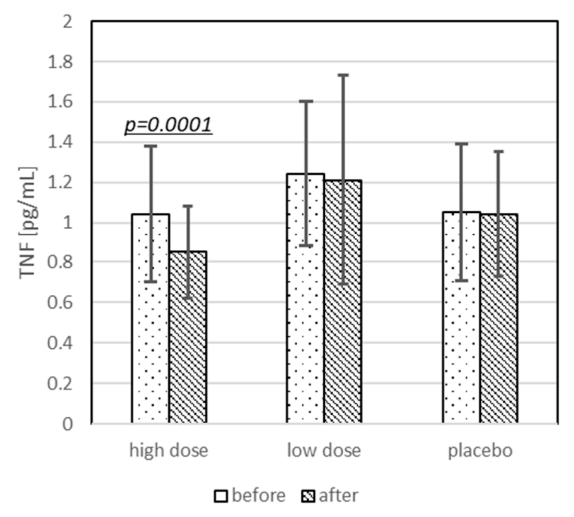

b)

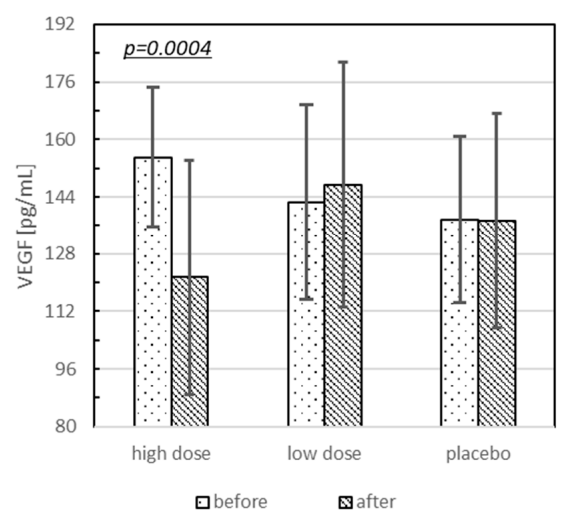

d)

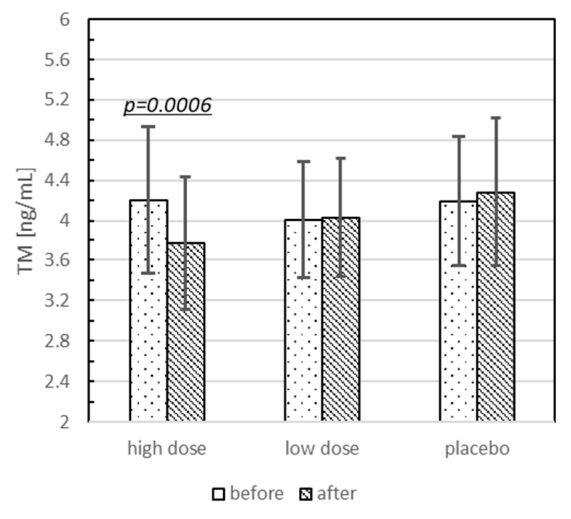

Figure 3. The comparison of the biochemical parameters in the high dose (HD), low dose (LD), and placebo groups at the beginning of the study and after three months of probiotic supplementation. Significant differences are highlighted showing the $p$-value. Data are arithmetic mean $\pm \mathrm{SD}$; (a) Il-6: interleukin-6; (b) VEGF: vascular endothelial growth factor; (c) TNF: tumor necrosis factor alpha; (d) TM: thrombomodulin.

Table 2. The comparison of the tested parameters in the high dose (HD), low dose (LD), and placebo groups at the beginning of the study and after three months of supplementation.

\begin{tabular}{cccccc}
\hline Variable & Group & Baseline & After 3 Months & SMD & $p$-Value \\
\hline & HD & $36.57 \pm 5.95$ & $36.22 \pm 5.29$ & 0.31 & 0.3165 \\
BMI & LD & $36.00 \pm 5.20$ & $35.51 \pm 5.16$ & 0.39 & 0.1209 \\
& Placebo & $36.10 \pm 4.37$ & $36.04 \pm 4.32$ & 0.07 & 0.9612 \\
& Functional parameters & & \\
& HD & $134.80 \pm 10.10$ & $131.40 \pm 9.41$ & 0.39 & $\mathbf{0 . 0 3 5 9}$ \\
SBP (mm Hg) & LD & $133.50 \pm 10.86$ & $130.88 \pm 9.42$ & 0.26 & $\mathbf{0 . 0 4 9 8}$ \\
& Placebo & $133.64 \pm 12.20$ & $131.52 \pm 12.31$ & 0.17 & 0.1795 \\
& HD & $79.88 \pm 8.05$ & $79.36 \pm 7.42$ & 0.07 & 0.7031 \\
DBP (mm Hg) & LD & $82.46 \pm 5.53$ & $81.73 \pm 6.40$ & 0.12 & 0.5095 \\
& Placebo & $83.76 \pm 7.26$ & $81.88 \pm 7.20$ & 0.26 & 0.2927 \\
& HD & $131.32 \pm 7.50$ & $121.75 \pm 11.14$ & 1.01 & $\mathbf{0 . 0 0 0 4}$ \\
PWA SP (mm Hg) & LD & $126.56 \pm 12.81$ & $127.28 \pm 16.53$ & -0.05 & 0.6997 \\
& Placebo & $127.23 \pm 12.43$ & $127.92 \pm 16.79$ & -0.04 & 0.8078 \\
PWA PP (mm Hg) & HD & $46.44 \pm 11.18$ & $40.63 \pm 8.65$ & 0.67 & $\mathbf{0 . 0 1 0 3}$ \\
& LD & $41.88 \pm 10.93$ & $41.45 \pm 14.07$ & 0.03 & 0.7989 \\
& Placebo & $46.35 \pm 10.65$ & $44.16 \pm 8.50$ & 0.26 & 0.3219 \\
PWA Alx & HD & $33.28 \pm 13.30$ & $27.56 \pm 9.94$ & 0.58 & $\mathbf{0 . 0 0 2 1}$ \\
& LD & $32.36 \pm 11.19$ & $33.48 \pm 11.12$ & -0.10 & 0.1711 \\
& Placebo & $33.62 \pm 10.30$ & $33.19 \pm 11.41$ & 0.04 & 0.8751 \\
PWV (m/s) & HD & $7.32 \pm 0.90$ & $6.45 \pm 0.77$ & 1.13 & $\mathbf{0 . 0 0 1 3}$ \\
& LD & $6.92 \pm 1.78$ & $6.74 \pm 1.29$ & 0.14 & 0.3536 \\
& Placebo & $6.90 \pm 0.94$ & $6.79 \pm 0.95$ & 0.12 & 0.3221 \\
\hline
\end{tabular}


Table 2. Cont

\begin{tabular}{cccccc}
\hline Variable & Group & Baseline & After 3 Months & SMD & $p$-Value \\
\hline & Biochemical parameters \\
& HD & $4.50 \pm 0.51$ & $4.41 \pm 0.59$ & 0.15 & $\mathbf{0 . 0 1 7 3}$ \\
IL-6 $(\mathrm{pg} / \mathrm{mL})$ & LD & $4.71 \pm 0.49$ & $4.50 \pm 1.15$ & 0.43 & $\mathbf{0 . 0 3 9 6}$ \\
& Placebo & $4.46 \pm 0.56$ & $4.45 \pm 4.45$ & 0.02 & 0.3282 \\
& HD & $155.04 \pm 19.38$ & $121.52 \pm 32.66$ & 1.73 & $\mathbf{0 . 0 0 0 4}$ \\
VEGF $(\mathrm{pg} / \mathrm{mL})$ & LD & $142.46 \pm 27.24$ & $147.35 \pm 34.19$ & -0.18 & 0.5991 \\
& Placebo & $137.64 \pm 23.20$ & $137.32 \pm 29.94$ & 0.01 & 0.7467 \\
& HD & $1.04 \pm 0.34$ & $0.85 \pm 0.23$ & 0.56 & $\mathbf{0 . 0 0 0 1}$ \\
$\mathrm{TNF}(\mathrm{pg} / \mathrm{mL})$ & LD & $1.24 \pm 0.36$ & $1.21 \pm 052$ & 0.08 & 0.2427 \\
& Placebo & $1.05 \pm 0.34$ & $1.04 \pm 0.31$ & 0.03 & 0.7610 \\
& HD & $4.20 \pm 0.73$ & $3.77 \pm 0.66$ & 0.59 & $\mathbf{0 . 0 0 0 6}$ \\
$\mathrm{TM}(\mathrm{ng} / \mathrm{mL})$ & LD & $4.01 \pm 0.58$ & $4.03 \pm 0.59$ & -0.03 & 0.8081 \\
& Placebo & $4.19 \pm 0.64$ & $4.28 \pm 0.74$ & -0.14 & 0.5938 \\
& HD & $84.86 \pm 6.40$ & $84.80 \pm 6.45$ & 0.01 & 0.8929 \\
$\mathrm{vWF}(\mathrm{ng} / \mathrm{mL})$ & LD & $83.90 \pm 5.71$ & $84.16 \pm 5.58$ & -0.05 & 0.8081 \\
& Placebo & $84.18 \pm 6.47$ & $83.55 \pm 5.96$ & 0.10 & 0.9544 \\
\hline
\end{tabular}

Significant differences are highlighted in bold. Data are the arithmetic mean \pm SD; SMD: standardized mean difference; BMI: body mass index; DBP: diastolic blood pressure; Il-6: interleukin-6; PWA Alx: pulse wave analysis augmentation index; PWA PP: pulse wave analysis pulse pressure; PWA SP: pulse wave analysis systolic pressure; PWV: pulse wave velocity; SBP: systolic blood pressure; TM: thrombomodulin; TNF: tumor necrosis factor alpha; VEGF: vascular endothelial growth factor; vWF: von Willebrand factor.

The mean $\Delta$ of the estimated parameters compared among the three groups revealed significant differences in VEGF $(p<0.0009)$, PWA SP (0.0016), PWA Alx (0.0084), PWV $(p<0.0028)$, TNF $(p<0.0012)$, and $\operatorname{TM}(p<0.0172)$.

The post hoc test showed statistically significant $\triangle$ VEGF $(p<0.0001, \mathrm{SMD}=-1.03), \triangle \mathrm{PWA} S \mathrm{SP}$ $(p=0.0054, \mathrm{SMD}=-1.00), \Delta \mathrm{PWA}$ Alx $(p=0.0079, \mathrm{SMD}=-0.55), \Delta \mathrm{PWV}(p=0.0045, \mathrm{SMD}=-0.82)$, $\Delta \mathrm{TNF}(p<0.0009, \mathrm{SMD}=-1.03), \Delta \mathrm{TM}(p<0.0194, \mathrm{SMD}=-0.78)$ when comparing the HD to the placebo group. For the HD and LD group comparisons, statistically significant $\triangle$ VEGF $(p<0.0007$, SMD $=-0.09), \Delta$ PWA SP $(p<0.0057$, SMD $=-0.91), \Delta \mathrm{PWV}(p<0.0189, \mathrm{SMD}=-0.55), \Delta \mathrm{TNF}$ $(p<0.0471, \mathrm{SMD}=-0.68)$ were observed (Table 3$)$.

Table 3. The changes in the biochemical and functional variables in the high dose (HD), low dose (LD), and placebo groups after three months.

\begin{tabular}{|c|c|c|c|c|c|}
\hline Variable & Group & Mean \pm SD & SMD & $p$-Value & $p$-Value Post-Hoc Test \\
\hline \multirow{4}{*}{$\Delta \mathrm{BMI}$} & HD & $-0.35 \pm 1.29$ & $-0.26 *$ & \multirow{3}{*}{0.6960} & \multirow{3}{*}{ ns } \\
\hline & LD & $-0.49 \pm 1.29$ & $-0.38^{+}$ & & \\
\hline & Placebo & $-0.06 \pm 0.87$ & $0.11^{\#}$ & & \\
\hline & \multicolumn{2}{|c|}{ Functional parameters } & & & \multirow{5}{*}{ ns } \\
\hline \multirow{4}{*}{$\Delta \mathrm{SBP}(\mathrm{mm} \mathrm{Hg})$} & $\mathrm{HD}$ & $-3.76 \pm 8.47$ & $-0.21 *$ & \multirow{4}{*}{0.7789} & \\
\hline & LD & $-2.62 \pm 9.63$ & $-0.06^{+}$ & & \\
\hline & Placebo & $-2.12 \pm 6.83$ & $-0.13^{\#}$ & & \\
\hline & HD & $-0.52 \pm 6.74$ & $0.17 *$ & & \\
\hline \multirow[t]{3}{*}{$\triangle \mathrm{DBP}(\mathrm{mm} \mathrm{Hg})$} & LD & $-0.73 \pm 5.57$ & $0.16^{+}$ & \multirow[t]{3}{*}{0.7677} & \multirow[t]{3}{*}{ ns } \\
\hline & Placebo & $-1.88 \pm 8.74$ & $0.03^{\#}$ & & \\
\hline & HD & $-9.57 \pm 10.87$ & $-1.00 *$ & & \\
\hline \multirow[t]{3}{*}{$\Delta$ PWA SP (mm Hg) } & LD & $0.72 \pm 12.49$ & $-0.01^{+}$ & \multirow[t]{3}{*}{0.0016} & \multirow[t]{3}{*}{${ }^{*} 0.0054{ }^{\#} 0.0057$} \\
\hline & Placebo & $0.69 \pm 10.61$ & $-0.91^{\#}$ & & \\
\hline & HD & $-5.92 \pm 10.55$ & $-0.37^{*}$ & & \\
\hline \multirow[t]{3}{*}{$\triangle$ PWA PP (mm Hg) } & LD & $-1.70 \pm 9.97$ & $0.02^{+}$ & \multirow[t]{3}{*}{0.1439} & \multirow[t]{3}{*}{ ns } \\
\hline & Placebo & $-1.88 \pm 11.10$ & $-0.41^{\#}$ & & \\
\hline & HD & $-5.72 \pm 8.84$ & $-0.55^{*}$ & & \\
\hline \multirow[t]{3}{*}{$\triangle \mathrm{PWA}$ Alx } & LD & $1.12 \pm 4.73$ & $0.19^{\dagger}$ & \multirow[t]{3}{*}{0.0084} & \multirow[t]{3}{*}{${ }^{*} 0.0079$} \\
\hline & Placebo & $-0.43 \pm 10.45$ & $-0.97^{\#}$ & & \\
\hline & HD & $-0.87 \pm 1.69$ & $-0.82 *$ & & \\
\hline \multirow[t]{2}{*}{$\Delta \mathrm{PWV}(\mathrm{m} / \mathrm{s})$} & LD & $-0.19 \pm 1.76$ & $-0.07^{\dagger}$ & \multirow[t]{2}{*}{0.0028} & \multirow[t]{2}{*}{${ }^{*} 0.0045$ \# 0.0189} \\
\hline & Placebo & $-0.10 \pm 0.58$ & $-0.55^{\#}$ & & \\
\hline
\end{tabular}


Table 3. Cont.

\begin{tabular}{|c|c|c|c|c|c|}
\hline Variable & Group & Mean \pm SD & SMD & $p$-Value & $p$-Value Post-Hoc Test \\
\hline \multicolumn{6}{|c|}{ Biochemical parameters } \\
\hline \multirow{4}{*}{$\Delta \mathrm{IL}-6(\mathrm{pg} / \mathrm{mL})$} & HD & $-0.09 \pm 0.02$ & $-0.38 *$ & & \\
\hline & LD & $-0.21 \pm 0.99$ & $-0.10^{\dagger}$ & 0.2461 & ns \\
\hline & Placebo & $-0.009 \pm 0.08$ & $-0.09^{\#}$ & & \\
\hline & HD & $-33.52 \pm 36.84$ & $-1.09 *$ & & \\
\hline \multirow[t]{3}{*}{$\Delta$ VEGF $(\mathrm{pg} / \mathrm{mL})$} & LD & $4.88 \pm 33.08$ & $0.20^{+}$ & 0.0001 & ${ }^{*} 0.0001{ }^{\#} 0.0007$ \\
\hline & Placebo & $-0.58 \pm 21.75$ & $-1.10^{\#}$ & & \\
\hline & HD & $-0.20 \pm 0.22$ & $-1.03 *$ & & \\
\hline \multirow[t]{3}{*}{$\Delta \mathrm{TNF}(\mathrm{pg} / \mathrm{mL})$} & LD & $-0.03 \pm 0.28$ & $-0.09^{\dagger}$ & 0.0012 & ${ }^{*} 0.0009{ }^{\#} 0.0471$ \\
\hline & Placebo & $-0.01 \pm 0.14$ & $-0.68^{\#}$ & & \\
\hline & HD & $-0.43 \pm 0.52$ & $-0.78 *$ & & \\
\hline \multirow[t]{3}{*}{$\Delta \mathrm{TM}(\mathrm{ng} / \mathrm{mL})$} & LD & $-0.14 \pm 1.03$ & $-0.25^{\dagger}$ & 0.0172 & $* 0.0194$ \\
\hline & Placebo & $0.09 \pm 0.79$ & $-0.36^{\#}$ & & \\
\hline & HD & $-0.07 \pm 6.64$ & $0.07^{*}$ & & \\
\hline \multirow[t]{2}{*}{$\Delta \mathrm{vwF}(\mathrm{ng} / \mathrm{mL})$} & $\mathrm{LD}$ & $0.12 \pm 5.13$ & $0.11^{\dagger}$ & 0.9915 & ns \\
\hline & Placebo & $-0.44 \pm 4.64$ & $-0.03^{\#}$ & & \\
\hline
\end{tabular}

Significant differences are highlighted in bold. Data are the arithmetic mean \pm SD; SMD: standardized mean difference; ns: not significant; BMI: body mass index; DBP: diastolic blood pressure; Il-6: interleukin-6; PWA Alx: pulse wave analysis augmentation index; PWA PP: pulse wave analysis pulse pressure; PWA SP: pulse wave analysis systolic pressure; PWV: pulse wave velocity; SBP: systolic blood pressure; TM: thrombomodulin; TNF: tumor necrosis factor alpha; VEGF: vascular endothelial growth factor; vWF: von Willebrand factor; $\Delta$ : change of the parameter. ${ }^{*} \mathrm{HD}$ : high dose of the probiotic group vs. Placebo; ${ }^{\dagger} \mathrm{LD}$ : low dose of the probiotic group vs. Placebo; \# HD vs. LD.

The proliferation grade of HUVEC exposed for $24 \mathrm{~h}$ to serum derived from the HD, LD, and placebo groups did not change significantly (Table 4).

Table 4. The proliferation grade of human umbilical vein endothelial cells (HUVEC) exposed for $24 \mathrm{~h}$ to serum derived from the high dose (HD), low dose (LD), and placebo groups before and after the intervention, estimated by an in vitro MTT colorimetric assay.

\begin{tabular}{ccccc}
\hline \multirow{2}{*}{ Variable } & \multicolumn{4}{c}{ Study Population } \\
\cline { 2 - 5 } & Group & Mean \pm SD & SMD & $p$-Value \\
\hline \multirow{2}{*}{$\%$ of control } & HD & $144.03 \pm 43.18$ & $-0.67^{*}$ & \\
before & LD & $160.83 \pm 32.07$ & $-0.30^{\dagger}$ & 0.1042 \\
& Placebo & $171.23 \pm 37.51$ & $-0.44^{\#}$ & \\
\% of control & HD & $159.68 \pm 38.42$ & $0.22^{*}$ & \\
after & LD & $163.50 \pm 33.88$ & $0.33^{\dagger}$ & 0.4502 \\
& Placebo & $151.12 \pm 39.96$ & $-0.11^{\#}$ & \\
Mean $\Delta$ & HD & $15.65 \pm 54.28$ & $0.72^{*}$ & \\
& LD & $2.67 \pm 30.78$ & $0.60^{\dagger}$ & 0.0529 \\
& Placebo & $-20.11 \pm 44.17$ & $0.29^{\#}$ & \\
\% of change & HD & $27.94 \pm 77.65$ & $0.65^{*}$ & \\
& LD & $3.28 \pm 20.48$ & $0.57^{\dagger}$ & 0.0513 \\
\% of control & Placebo & $-9.77 \pm 25.29$ & $0.43^{\#}$ & \\
before vs. after & HD & 144.03 vs. 159.68 & -0.27 & 0.1821 \\
& LD & 160.83 vs. 163.50 & -0.09 & 0.7716 \\
\hline
\end{tabular}

Data are the arithmetic mean \pm SD; SMD: standardized mean difference; $\Delta$ : change of the parameter. Control; means cells maintained in standard culture medium without patient serum. * HD: high dose of the probiotic group vs. Placebo; ${ }^{\dagger}$ LD: low dose of the probiotic group vs. Placebo; ${ }^{\#}$ HD vs. LD.

In individuals who received probiotics after 12 weeks of study, a significant relationship was documented between the post-intervention SBP and the PWV values $(r=0.46)$, the post-intervention SBP PWA PP values $(r=0.54)$, and between the post-intervention DPB value and the $\triangle \mathrm{PWV}(r=-0.43)$, and between the DBP value and the post-intervention TNF value $(r=0.49)$. The correlations between the IL-6 value and the PWA SP value after intervention $(r=0.46)$, the IL- 6 value after intervention, and the $\Delta \mathrm{TNF}(r=-0.48)$ and $\Delta \mathrm{TM}(r=-0.39)$ values were documented. The post-intervention $\mathrm{TM}$ 
value was significantly associated with the post-intervention SBP value $(r=0.41)$, the post-intervention DBP value $(r=0.63)$, and the post-intervention PWA Alx value $(r=-0.41)$ (Table 5).

Table 5. The significant correlations in the high dose (HD) and low dose (LD) groups.

\begin{tabular}{cccc}
\hline Group & Correlated Parameters & $p$ & $\boldsymbol{r}$ \\
\hline \multirow{4}{*}{ LD } & SBP II \& PWV II & 0.0181 & 0.46 \\
& DBP II \& $\Delta$ PWV & 0.0252 & -0.43 \\
& IL-6 II \& $\Delta$ TM & 0.0482 & -0.39 \\
& sTM II \& PWA Alx II & 0.0401 & -0.41 \\
& SBP II \& PWA PP II & 0.0174 & 0.54 \\
& DBP II \& TNF II & 0.0121 & 0.49 \\
HD & IL-6 II \& PWA SP II & 0.0229 & 0.46 \\
& IL-6 II \& $\Delta$ TNF & 0.0249 & -0.48 \\
& TM II \& SBP II & 0.0278 & 0.41 \\
& TM II \& DBP II & 0.0058 & 0.63 \\
\hline
\end{tabular}

I: the value of the parameter at baseline; II: the value of the parameter after completion; $\Delta$ : change of the parameter; $r$ : Spearman correlation index. DBP: diastolic blood pressure; Il-6: interleukin-6; PWA Alx: pulse wave analysis augmentation index; PWA PP: pulse wave analysis pulse pressure; PWA SP: pulse wave analysis systolic pressure; PWV: pulse wave velocity; SBP: systolic blood pressure; TM: thrombomodulin; TNF: tumor necrosis factor alpha.

\section{Discussion}

The previous literature has widely discussed the role of probiotics in the treatment of cardiovascular diseases. However, despite the research carried out, knowledge about this topic is still incomplete. In our work, we investigated the extent to which supplementation with selected multi-probiotics can improve the function of the arterial endothelium in obese individuals.

The novelty of this work is first, in the assessment of not only biochemical parameters, but also in the functional parameters indicating endothelial function, and, second, in the participation of postmenopausal obese women in the trial, who have a significantly increased risk of developing CVD. The third novel approach was the use of dose-dependent supplementation of a composed multispecies probiotic, Ecologic ${ }^{\circledR}$ Barrier, containing a selected range of bacterial strains.

In recent years, the emphasis has been placed on the role of arterial stiffness in the development of cardiovascular diseases [32,33]. There is a multitude of available methods available to test this parameter, among which PWV is generally considered to be the most precise way to non-invasively estimate arterial stiffness in humans. Indeed, a wide range of studies has shown that high PWV values are associated with increased arterial stiffness and increased risk for cardiovascular disease [34,35]. PWA is another modality that evaluates arterial function [36]. The central aortic hemodynamic parameters derived by PWA include PP, AP, and Alx, reliable markers for estimating arterial stiffness [36]. A significant association between blood pressure and the PWV and PWA values was also present in our study. It should be noted that in our work, the initial PWV values did not cross the reference values $(12 \mathrm{~m} / \mathrm{s})$, but we also rated this parameter in the studied groups after the intervention. When comparing PWV at the beginning of the study and after 12 weeks, a statistically significant decrease in the HD group was demonstrated. No similar trend was found in the LD and placebo groups. Interestingly, a significant decrease was observed in the PWV change in the HD group and LD group compared to the placebo after the intervention, as well as a difference depending on the dose of the probiotic. The way in which probiotics affect the endothelium is not fully understood and depends on a number of factors: the number of individual strains, the age of the study group, concomitant diseases, the method of administration, and the dosage of the preparation [22,37]. Menni et al. have shown that gut microbial diversity is associated with lower arterial stiffness in healthy women [38]. Other factors that may be involved in the development of arterial stiffness are insulin resistance and lipid metabolism disturbances [39]. In our previous study, we showed that the Ecologic ${ }^{\circledR}$ Barrier supplementation favorably affects cardiovascular risk factors in a dose-dependent manner, showing beneficial effects on cardiometabolic parameters, including the lipid metabolism 
and insulin resistance, as well as gut permeability [25]. Sabico et al. observed that Ecologic ${ }^{\circledR}$ Barrier supplementation for six months caused a significant decrease in insulin resistance, and improved the lipid and carbohydrate metabolism [24]. The drop in PWV in the studied population after the Ecologic ${ }^{\circledR}$ Barrier supplementation seems to be the result of the above-mentioned phenomena, and this requires further research.

In the HD and LD groups, a significant decrease in SBP was observed between the values at the beginning and end of the study. The significant correlation between SBP and PWV demonstrated in our study confirms the dependence of PWV on the SBP value [40].

In terms of pre versus post-intervention values, similar trends were observed for PWA SP, PWA PP, and PWA Alx. After 12 weeks of intervention, significant differences were demonstrated for PWA SP and PWA Alx, and an effect depending on the dose was observed for PWA SP only. The obtained results are highly innovative, and so far, the above parameters have not been assessed in obese women after menopause undergoing a 12-week supplementation with the selected probiotic preparation.

An important issue is whether the decrease in PWV and PWA decrease due to probiotic supplementation improves endothelial function. To confirm this, it is necessary to find other parameters that are sensitive enough to reflect an improvement in endothelial function. However, current methods for estimating endothelial cell biomarkers show discrepancies. Most of the previous research, while reflecting endothelial cell dysfunction, displayed a decline in proinflammatory biomarkers [41,42]. In our study, PWA SP was significantly correlated with serum Il-6 concentration, and an inverse relation between IL-6 and delta TNF was documented. However, it should be emphasized that dysfunctions in smooth muscle cells may also contribute to an increased vascular tone, remodeling, and vasoreactivity in patients with cardiovascular diseases [43]. Undoubtedly, an extension of the research methods, e.g., the measurement of flow-mediated dilation or venous occlusion plethysmography, nitric oxide bioavailability, and reactive oxygen species level, would provide more information on the endothelium-mediated functional improvement of the patient after probiotic treatment. However, it is known that chronic inflammation is an important factor in the pathogenesis of endothelial dysfunction in obese people $[44,45]$. Disorders of the intestinal microbiota lead to the leakage of the intestinal barrier, which leads to the penetration of endotoxins into the blood and the subsequent development of the subclinical inflammatory process. The blood concentration of inflammatory cytokines such as TNF- $\alpha$ and Il-6 increases [46,47]. Accordingly, we observed significant decreases in TNF- $\alpha$ and Il-6 in probiotic-supplemented women, but not in the placebo group. In addition, in the case of TNF, the effect was dose-dependent. The ability to modulate inflammation depends on the type and strain of bacteria that are components of the probiotic preparation. Jafarneid et al. showed that a preparation containing the lactic acid bacteria reduced the concentrations of TNF- $\alpha$ and IL- 6 in the group of women with gestational diabetes [48]. Similarly, the administration of Lactobacillus casei 01 bacteria to patients with rheumatoid arthritis significantly decreased TNF- $\alpha[49,50]$. Our previous study, as well as a study by Subico et al., confirmed the anti-inflammatory- and intestinal barrier-improving properties of Ecologic ${ }^{\circledR}$ Barrier [24,25].

Visceral fat is well vascularized, and it shows greater angiogenesis capacity; moreover, it more easily induces inflammation [51,52]. The role of TNF- $\alpha$ in the process of angiogenesis remains unclear. Perhaps TNF- $\alpha$ stimulates endothelial cells to increase the synthesis of proangiogenic factors such as interleukin-8 (Il-8), VEGF, and the basic fibroblast growth factor bFGF. The expression of Il-8 and VEGF is regulated by the activation of the nuclear transcription factor kappa B (NF- $\mathrm{B}$ ), while bFGF is partially regulated by the activation of the AP-1 transcription factor [53]. The chronic effects of pro-inflammatory TNF- $\alpha$ on endothelial cells reduce the synthesis of VEGF and its receptors [54]. TNF- $\alpha$ is thought to be the major cytokine contributing to endothelial dysfunction, leading to inflammatory activation [55].

The administration of multispecies probiotic supplements significantly decreased the VEGF level. Previous investigations of the influence of probiotics on the VEGF level have been limited to a few mentioned studies, mainly in animal models, and in patients with non-obesity chronic inflammatory diseases. Marlicz et al. showed that short-term probiotic mixture (VSL\#3) administration 
affects several clinical and biochemical parameters, including VEGF, which is commonly altered in liver cirrhosis [56]. Li et al. demonstrated that Lactobacillus rhamnosus reduces Lipopolysaccharides (LPS)-induced anti-inflammatory cytokines IL-1RN, IL-4 and IL-10, and LPS-induced VEGF output [57]. Other studies indicated that the probiotic yeast Saccharomyces boulardii can modulate angiogenesis to limit intestinal inflammation and to promote mucosal tissue repair by regulating VEGFR signaling [58]. It is well known that VEGF acts on endothelial cells by regulating its proliferation and migration grade. Therefore, we performed an in vitro study to assess the putative ability of serum derived from our patients before and after probiotic supplementation, to act on HUVEC proliferation. Surprisingly, despite the significantly decreased VEGF level observed in obese women supplemented with high doses of probiotics, both the mean changes in HUVEC number and the percentage of change of cells exposed to serum from the HD group showed increasing trends, although the differences were not quite significant. The discrepancy between the results may be explained by the antiangiogenic potential of VEGF. Moreover, experiments that measure the change of endothelial nitric oxide synthase expression and activity, reactive oxygen species production, tight junction protein level, and endothelial permeability in response to patient serum would provide a more mechanistic insight into the role of the endothelium. Recently, Ngo et al. demonstrated that impaired angiogenesis, which is associated with obesity, may be driven by the antiangiogenic isoform $V_{E G F}{ }_{165 b}$ [59]. The authors demonstrated that obese patients are characterized by elevated serum levels of $V_{E G F}{ }_{165} b$ compared to lean individuals. Recently, in an in vitro study, Yanagihara et al. proved that exposure to the probiotic Lactobacillus acidophilus L-92 modulates the expression of genes that are involved in splicing in epithelial Caco-2 cells [60]. The antibody used in our study does not distinguish between angiogenic and antiangiogenic VEGF; nevertheless, here, we demonstrated, for the first time, that multispecies probiotic supplementation could decrease VEGF serum levels in postmenopausal women with obesity in a dose-dependent manner; thus, studies including the usage of a $\mathrm{VEGF}_{165 \mathrm{~b}}$ antibody are needed to draw further conclusions.

An important role of the endothelium is its involvement in the regulation of blood coagulation. Data concerning changes in other parameters of endothelial cell function, including as a mediator of coagulation and fibrinolysis, are limited in the literature. Our study demonstrated that a multispecies probiotic has a beneficial impact on the TM level in obese postmenopausal women by the significant decrease in the HD group observed after probiotic supplementation without any changes seen in the placebo-receiving individuals. TM is one of the most sensitive and specific markers of endothelial damage; it changes the properties of thrombin with a simple anticoagulant [61]. The concentration of free TM has been repeatedly found in high-risk CVD patients. Disconnected from the endothelium, transmembrane fragments can be considered as a marker of endothelial cell injury and thus, an early marker of atherosclerosis [61]. In our study, TM was significantly correlated with functional parameters of endothelium dysfunction, such as PWA Alx, or PWA AP, and blood pressure values. Concerning biochemical parameters, delta TM is inversely correlated with Il-6. The influence of targeted probiotics on TM in obesity has not been studied so far. Recently, Zelaya et al. studied the effects of intranasal Lactobacillus Rhamnosus therapy on coagulation parameters, including TM [62]. Our work is clinically relevant, and thus, for the first time, it demonstrates the ability of a specific probiotic supplementation to beneficially modulate a coagulation biomarker in obese postmenopausal women.

The strengths of the current study are the design (a randomized, placebo-controlled, double-blind intervention), the use of a panel of analyzed endothelial parameters (functional and biochemical), and the dose-dependent efficacy analysis.

The major limitation of this study is the relatively small number of individuals examined. The main reason for this was the rigorous inclusion and exclusion criteria. However, the applied criteria enabled us to select a homogenous group of subjects who were not affected by diseases or states that might have significantly influenced the results of the study. Although in the current, as well as our former study, we observed that probiotic administration resulted in an anti-inflammatory effect (decreased IL-6 and TNF- $\alpha$ ), as well as a reduced LPS translocation, we consider the lack of the analysis 
of microbial composition and their metabolites in feces as another limitation which could demonstrate the influence of probiotic bacteria on the gut microbiota composition, as well as its potential metabolic activity. This missing information would shed more light on the mechanism of the probiotic effect on vascular function and arterial stiffness. It would be also interesting to perform more detailed studies of probiotics effects on the gut barrier.

\section{Conclusions}

In this randomized double-blind placebo-controlled 12-week trial, we showed, for the first time, that supplementation with the multispecies probiotic supplement Ecologic ${ }^{\circledR}$ Barrier favorably modifies both functional and biochemical markers of vascular dysfunction in obese postmenopausal women. The role of multispecies probiotic supplements in cardiovascular prevention needs further investigation, but it appears that it could be a useful therapy for obese patients.

Author Contributions: Conceived and designed the experiments: all authors. Performed the experiments: M.S. (Monika Szulińska), P.B. and K.S. Analyzed the data: M.S. (Monika Szulińska), P.B., M.S. (Magdalena Sobieska) and I.Ł. Wrote the paper: all authors. All authors revised and approved the final version of the manuscript. The datasets used and/or analyzed during the current study are available from the corresponding author on request.

Funding: This research was funded by the internal sources (statutory funds) of the University of Medical Sciences in Poznań. The APC was funded by Sanprobi sp. z o.o. sp. k.

Acknowledgments: Trial registration: ClinicalTrails.gov Identifier: NCT03100162. We would like to thank Agnieszka Seraszak-Jaros from the Department of Bioinformatics and Computational Biology in the Chair of Clinical Pathomorphology, Poznan University of Medical Sciences, and Mariusz Kaczmarczyk from the Department of Clinical and Molecular Biochemistry, Pomeranian Medical University, Szczecin, for their assistance with the statistics used in this study. Winclove Probiotics kindly supplied both the active and the placebo products, but did not have any additional role in the study design, data collection, and analysis, decision to publish, or preparation of the manuscript. We would like also to thank MDPI (http:/ / www.mdpi.com/authors/english) for English language editing.

Conflicts of Interest: I.Ł. is a foundation shareholder in Sanprobi, a probiotics distributor. However, the content of this study was not constrained by this fact. Moreover, our adherence to Nutrients' policies on the sharing of data and materials was unaffected. The other authors have no conflicts of interest to declare.

\section{References}

1. Barton, M. Endothelin in the microvasculature. In W: Microvascular Research: Biology and Pathology; Shepro, D., Ed.; Elsevier Academic Press: San Diego, CA, USA, 2006; pp. 5-12.

2. Sagach, V.; Bondarenko, A.; Bazilyuk, O.; Kotsuruba, A. Endothelial dysfunction: Possible mechanisms and ways of correction. Exp. Clin. Cardiol. 2006, 11, 107-110. [PubMed]

3. Sivitz, W.I.; Wayson, S.M.; Bayless, M.L.; Sinkey, C.A.; Haynes, W.G. Obesity impairs vascular relaxation in human subjects: Hyperglycemia exaggerates adrenergic vasoconstriction arterial dysfunction in obesity and diabetes. J. Diabetes Complicat. 2007, 21, 149-157. [CrossRef] [PubMed]

4. Mundy, A.L.; Haas, E.; Bhattacharya, I.; Widmer, C.C.; Kretz, M.; Hofmann-Lehmann, R.; Minotti, R.; Barton, M. Fat intake modifies vascular responsiveness and receptor expression of vasoconstrictors: Implications for diet-induced obesity. Cardiovasc. Res. 2007, 73, 368-375. [CrossRef] [PubMed]

5. Hanson, M.; Gluckman, P. Endothelial dysfunction and cardiovascular disease: The role of predictive adaptive responses. Heart 2005, 91, 864-866. [CrossRef] [PubMed]

6. Bolad, I.; Delafontaine, P. Endothelial dysfunction: Its role in hypertensive coronary disease. Curr. Opin. Cardiol. 2005, 20, 270-274. [CrossRef] [PubMed]

7. Barton, M.; Baretella, O.; Meyer, M.R. Obesity and risk of vascular disease: Importance of endothelium-dependent vasoconstriction. Br. J. Pharmacol. 2012, 165, 591-602. [CrossRef] [PubMed]

8. Trojan, P.; Janik, M.; Przybyło, M. Śródbłonek-niedoceniany organ. 1. Budowa i rola w procesach fizjologicznych. Kosm. Probl. Nauk Biol. 2014, 4, 555-568.

9. Tam, J.; Duda, D.G.; Perentes, J.Y.; Quadri, R.S.; Fukumura, D.; Jain, R.K. Blockade of VEGFR2 and not VEGFR1 can limit diet-induced fat tissue expansion: Role of local versus bone marrow-derived endothelial cells. PLoS ONE 2009, 4, e4974. [CrossRef] [PubMed] 
10. Huang, A.L.; Vita, J.A. Effects of systemic inflammation on endothelium-Dependent vasodilation. Trends Cardiovasc. Med. 2006, 16, 15-20. [CrossRef] [PubMed]

11. Vilahur, G.; Ben-Aicha, S.; Badimon, L. New insights into the role of adipose tissue in thrombosis. Thromb. Haemost. 2013, 110, 669-680. [CrossRef] [PubMed]

12. Morange, P.E.; Alessi, M.C. Thrombosis in central obesity and metabolic syndrome: Mechanisms and epidemiology. Cardiovasc. Res. 2017, 113, 1046-1054. [CrossRef] [PubMed]

13. Aird, W.C. Natural anticoagulant inhibitors activated protein C. Best Pract. Res. Clin. Hematol. 2004, 17, 161-182. [CrossRef] [PubMed]

14. Sadler, J.E. Biochemistry and genetics of von Willebrand factor. Annu. Rev. Biochem. 1998, 67, $395-424$. [CrossRef] [PubMed]

15. Cieślik-Guerra, U. Methods of arterial stiffness measurement. Arter. Hypertens. 2011, 15, 42-48.

16. Lane, H.A.; Smith, J.C.; Davies, J.S. Noninvasive assessment of preclinical atherosclerosis. Vasc. Health Risk Manag. 2006, 2, 19-30. [CrossRef] [PubMed]

17. Bogdański, P.; Suliburska, J.; Szulińska, M.; Sikora, M.; Walkowiak, J.; Jakubowski, H. L-Arginine and vitamin $\mathrm{C}$ attenuate pro-atherogenic effects of high-fat diet on biomarkers of endothelial dysfunction in rats. Biomed. Pharmacother. 2015, 76, 100-106. [CrossRef] [PubMed]

18. Bogdanski, P.; Szulinska, M.; Suliburska, J.; Pupek-Musialik, D.; Jablecka, A.; Witmanowski, H. Supplementation with L-arginine favorably influences plasminogen activator inhibitor type 1 concentration in obese patients. A randomized, double blind trial. J. Endocrinol. Investig. 2013, 36, 221-226.

19. Miczke, A.; Szulińska, M.; Hansdorfer-Korzon, R.; Kręgielska-Narożna, M.; Sluliburska, J.; Walkowiak, J.; Bogdański, P. Effects of spirulina consumption on body weight, blood pressure, and endothelial function in overweight hypertensive Caucasians: A doubleblind, placebo-controlled, randomized trial. Eur. Rev. Med. Pharmacol. Sci. 2016, 20, 150-156. [PubMed]

20. Szulińska, M.; Kręgielska-Narożna, M.; Świątek, J.; Styś, P.; Kuźnar-Kamińska, B.; Jakubowski, H.; Walkowiak, J.; Bogdański, P. Garlic extract favorably modifies markers of endothelial function in obese patients-randomized double blind placebo-controlled nutritional intervention. Biomed. Pharmacother. 2018, 102, 792-797. [CrossRef] [PubMed]

21. Szulińska, M.; Stępień, M.; Kręgielska-Narożna, M.; Suliburska, J.; Skrypnik, D.; Bąk-Sosnowska, M.; Kujawska-Łuczak, M.; Grzymisławska, M.; Bogdański, P. Effects of green tea supplementation on inflammation markers, antioxidant status and blood pressure in $\mathrm{NaCl}$-induced hypertensive rat model. Food Nutr. Res. 2017, 61, 1295525. [CrossRef] [PubMed]

22. Brown, J.M.; Hazen, S.L. The gut microbial endocrine organ: Bacterially derived signals driving cardiometabolic diseases. Annu. Rev. Med. 2015, 66, 343-359. [CrossRef] [PubMed]

23. Van Hemert, S.; Ormel, G. Influence of the multispecies probiotic Ecologic ${ }^{\circledR}$ BARRIER on parameters of intestinal barrier function. Food Nutr. Sci. 2014, 5, 1739-1745.

24. Sabico, S.; Al-Mashharawi, A.; Al-Daghri, N.; Yakout, S.; Alnaami, M.; Alokail, M.; McTernan, F. Effects of a multi-strain probiotic supplement for 12 weeks in circulating endotoxin levels and cardiometabolic profiles of medication naïve T2DM patients: A randomized clinical trial. J. Transl. Med. 2017, 15, 249. [CrossRef] [PubMed]

25. Szulińska, M.; Łoniewski, I.; van Hemert, S.; Sobieska, M.; Bogdański, P. Dose-dependent effects of multispecies probiotic supplementation on the Lipopolysaccharide (LPS) level and cardiometabolic profile in obese postmenopausal women: A 12-Week randomized clinical trial. Nutrients 2018, 10, 773. [CrossRef] [PubMed]

26. Qureshi, G.; Brown, R.; Salciccioli, L. Relationship between aortic atherosclerosis and non-invasive measures of arterial stiffness. Atherosclerosis 2007, 195, E190-E194. [CrossRef] [PubMed]

27. Van Bortel, L.M.; Laurent, S.; Boutouyrie, P.; Chowienczyk, P.; Cruickshank, J.K.; De Backer, T. Artery Society; European Society of Hypertension Working Group on Vascular Structure and Function; European Network for Noninvasive Investigation of Large Arteries. Expert consensus document on the measurement of aortic stiffness in daily practice using carotid-femoral pulse wave velocity. J. Hypertens. 2012, 30, 445-448. [PubMed]

28. O'Rourke, M.F. Wave travel and reflection in the arterial system. J. Hypertens. Suppl. 1999, 17, S45-S47. [PubMed] 
29. Edgell, C.J.; McDonald, C.C.; Graham, J.B. Permanent cell line expressing human factor VIII-related antigen established by hybridization. Proc. Natl. Acad. Sci. USA 1983, 80, 3734-3737. [CrossRef] [PubMed]

30. Mosmann, T. Rapid colorimetric assay for cellular growth and survival: Application to proliferation and cytotoxicity assays. J. Immunol. Methods 1983, 65, 55-63. [CrossRef]

31. Witowski, J.; Korybalska, K.; Wisniewska, J.; Breborowicz, A.; Gahl, G.M.; Frei, U.; Passlick-Deetjen, J.; Jörres, A. Effect of glucose degradation products on human peritoneal mesothelial cell function. J. Am. Soc. Nephrol. 2000, 11, 729-739. [PubMed]

32. Vlachopoulos, C.; Aznaouridis, K.; Stefanadis, C. Aortic stiffness for cardiovascular risk prediction: Just measure it, just do it! J. Am. Coll. Cardiol. 2014, 63, 647-649. [CrossRef] [PubMed]

33. Laurent, S.; Kingwell, B.; Bank, A.; Weber, M.; Struijker-Boudier, H. Clinical applications of arterial stiffness: Therapeutics and pharmacology. Am. J. Hypertens. 2002, 15, 453-458. [CrossRef]

34. O’Rourke, M.F.; Staessen, J.A.; Vlachopoulos, C.; Duprez, D.; Plante, G.E. Clinical applications of arterial stiffness; definitions and reference values. Am. J. Hypertens. 2002, 15, 426-444. [CrossRef]

35. Pannier, B.M.; Avolio, A.P.; Hoeks, A.; Mancia, G.; Takazawa, K. Methods and devices for measuring arterial compliance in humans. Am. J. Hypertens. 2002, 15, 743-753. [CrossRef]

36. Laurent, S.; Cockcroft, J.; Van Bortel, L.; Boutouyrie, P.; Giannattasio, C.; Hayoz, D.; Pannier, B.; Vlachopoulos, C.; Wilkinson, I.; Struijker-Boudier, H.; et al. European network for non-invasive investigation of large arteries. Expert consensus document on arterial stiffness: Methodological issues and clinical applications. Eur. Heart J. 2006, 27, 2588-2605. [CrossRef] [PubMed]

37. Ebel, B.; Lemetis, G.; Beney, L.; Cachon, R.; Sokol, H.; Langella, P.; Gervais, P. Impact of probiotics on risk factors for cardiovascular diseases. A review. Crit. Rev. Food Sci. Nutr. 2014, 54, 175-189. [CrossRef] [PubMed]

38. Menni, C.; Lin, C.; Cecelja, M.; Mangino, M.; Matey-Hernandez, M.L.; Keehn, L.; Mohney, R.P.; Steves, C.J.; Spector, T.D.; Kuo, C.F.; et al. Gut microbial diversity is associated with lower arterial stiffness in women. Eur. Heart J. 2018, 39, 2390-2397. [CrossRef] [PubMed]

39. Rizzoni, D.; Porteri, E.; Guelfi, D.; Muiesan, M.L.; Valentini, U.; Cimino, A.; Girelli, A.; Rodella, L.; Bianchi, R.; Sleiman, I.; et al. Structural alterations in subcutaneous small arteries of normotensive and hypertensive patients with non-insulindependent diabetes mellitus. Circulation 2001, 103, 1238-1244. [CrossRef] [PubMed]

40. Rehman, A.; Rahman, A.R.; Rasool, A.H. Effect of angiotensin II on pulse wave velocity in humans is mediated through angiotensin II type 1 (AT(1)) receptors. J. Hum. Hypertens. 2002, 16, 261-266. [CrossRef] [PubMed]

41. Gøbel, R.J.; Larsen, N.; Jakobsen, M.; Mølgaard, C.; Michaelsen, K.F. Probiotics to adolescents with obesity: Effects on inflammation and metabolic syndrome. J. Pediatr. Gastroenterol. Nutr. 2012, 55, 673-678. [CrossRef] [PubMed]

42. Everard, A.; Matamoros, S.; Geurts, L.; Delzenne, N.M.; Cani, P.D. Saccharomyces boulardii administration changes gut microbiota and reduces hepatic steatosis, low-grade inflammation, and fat mass in obese and type 2 diabetic $\mathrm{db} / \mathrm{db}$ mice. mBio 2014, 5, e01011-14. [CrossRef] [PubMed]

43. Finney, A.C.; Orr, A.W. Guidance Molecules in Vascular Smooth Muscle. Front. Physiol. $2018,9,1311$. [CrossRef] [PubMed]

44. Wang, H.; Wang, Q.; Venugopal, J.; Wang, J.; Kleiman, K.; Guo, C.; Eitzman, D.T. Obesity-induced endothelial dysfunction is prevented by neutrophil extracellular trap inhibition. Sci. Rep. 2018, 8, 4881. [CrossRef] [PubMed]

45. Korybalska, K.; Luczak, J.; Swora-Cwynar, E.; Kanikowska, A.; Czepulis, N.; Kanikowska, D.; Skalisz, H.; Breborowicz, A.; Grzymislawski, M.; Witowski, J. Weight loss-dependent and -independent effects of moderate calorie restriction on endothelial cell markers in obesity. J. Physiol. Pharmacol. 2017, 68, 597-608. [PubMed]

46. De Andrés, J.; Manzano, S.; García, C.; Rodríguez, J.M.; Espinosa-Martos, I.; Jiménez, E. Modulatory effect of three probiotic strains on infants' gut microbial composition and immunological parameters on a placebo-controlled, double-blind, randomised study. Benef. Microbes 2018, 9, 573-584. [CrossRef] [PubMed]

47. Eom, T.; Kim, Y.S.; Choi, C.H.; Sadowsky, M.J.; Unno, T. Current understanding of microbiota- and dietary-therapies for treating inflammatory bowel disease. J. Microbiol. 2018, 56, 189-198. [CrossRef] [PubMed] 
48. Jafarnejad, S.; Saremi, S.; Jafarnejad, F. Effects if multispecies probiotic mixture on glycemic control and inflammatory status in women with gestational diabetes: A randomized controlled clinical trial. J. Am. Coll. Nutr. 2017, 36, 497-506. [CrossRef] [PubMed]

49. Vaghef-Mahrabany, E.; Alipour, B.; Homayouni-Rad, A. Probiotic supplementation improves inflammatory status in patient with rheumatoid arthritis. Nutrition 2014, 30, 430-435. [CrossRef] [PubMed]

50. Hatakka, K.; Martio, J.; Korpela, M. Effects of probiotic therapy on the acticity and activation of mild rheumatoid arthritis-A pilot study. Scand. J. Rheumatol. 2003, 32, 211-215. [CrossRef] [PubMed]

51. Tang, W.; Zeve, D.; Suh, J.M.; Bosnakovski, D.; Kyba, M.; Hammer, R.E.; Tallquist, M.D.; Graff, J.M. White fat progenitor cells reside in the adipose vasculature. Science 2008, 322, 583-586. [CrossRef] [PubMed]

52. Villaret, A.; Galitzky, J.; Decaunes, P.; Esteve, D.; Marques, M.A.; Sengenès, C.; Chiotasso, P.; Tchkonia, T.; Lafontan, M.; Kirkland, J.L.; et al. Adipose tissue endothelial cells from obese human subjects: Differences among depots in angiogenic, metabolic, and inflammatory gene expression and cellular senescence. Diabetes 2010, 59, 2755-2763. [CrossRef] [PubMed]

53. Yoshida, S.; Ono, M.; Shono, T.; Izumi, H.; Ishibashi, T.; Suzuki, H.; Kuwano, M. Involvement of interleukin-8, vascular endothelial growth factor, and basic fibroblast growth factor in tumor necrosis factor alpha-dependent angiogenesis. Mol. Cell. Biol. 1997, 17, 4015-4023. [CrossRef] [PubMed]

54. Patterson, C.; Perrella, M.A.; Endege, W.O.; Yoshizumi, M.; Lee, M.E.; Haber, E. Downregulation of Vascular Endothelial Growth Factor Receptors by Tumor Necrosis Factor-a in Cultured Human Vascular Endothelial Cells. J. Clin. Investig. 1996, 98, 490-496. [CrossRef] [PubMed]

55. Ouchi, N.; Kihara, S.; Arita, Y.; Maeda, K.; Kuriyama, H.; Okamoto, Y.; Hotta, K.; Nishida, M.; Takahashi, M.; Nakamura, T.; et al. Novel modulator for endothelial adhesion molecules: Adipocyte-derived plasma protein adiponectin. Circulation 1999, 100, 2473-2476. [CrossRef] [PubMed]

56. Marlicz, W.; Wunsch, E.; Mydlowska, M.; Milkiewicz, M.; Serwin, K.; Mularczyk, M.; Milkiewicz, P.; Raszeja-Wyszomirska, J. The effect of short term treatment with probiotic VSL\#3 on various clinical and biochemical parameters in patients with liver cirrhosis. J. Physiol. Pharmacol. 2016, 67, 867-877. [PubMed]

57. Li, W.; Yang, S.; Kim, S.O.; Reid, G.; Challis, J.R.; Bocking, A.D. Lipopolysaccharide-Induced Profiles of Cytokine, Chemokine, and Growth Factors Produced by Human Decidual Cells Are Altered by Lactobacillus rhamnosus GR-1 Supernatant. Reprod. Sci. 2014, 21, 939-947. [CrossRef] [PubMed]

58. Chen, X.; Yang, G.; Song, J.H.; Xu, H.; Li, D.; Goldsmith, J.; Zeng, H.; Parsons-Wingerter, P.A.; Reinecker, H.C.; Kelly, C.P. Probiotic yeast inhibits VEGFR signaling and angiogenesis in intestinal inflammation. PLoS ONE 2013, 8, e64227. [CrossRef] [PubMed]

59. Ngo, D.T.; Farb, M.G.; Kikuchi, R.; Karki, S.; Tiwari, S.; Bigornia, S.J.; Bates, D.O.; LaValley, M.P.; Hamburg, N.M.; Vita, J.A.; et al. Antiangiogenic actions of vascular endothelial growth factor-A165b, an inhibitory isoform of vascular endothelial growth factor-A, in human obesity. Circulation 2014, 130, 1072-1080. [CrossRef] [PubMed]

60. Yanagihara, S.; Fukuda, S.; Ohno, H.; Yamamoto, N. Exposure to probiotic Lactobacillus acidophilus L-92 modulates gene expression profiles of epithelial Caco-2 cells. J. Med. Food 2012, 15, 511-519. [CrossRef] [PubMed]

61. Schumacher, A.; Seljeflot, I.; Sommervoll, L.; Christensen, B.; Otterstad, J.E.; Arnesen, H. Increased levels of endothelial haemostatic markers in patients with coronary heart disease. Thromb. Res. 2002, 105, 25-31. [CrossRef]

62. Zelaya, H.; Tada, A.; Vizoso-Pinto, M.G.; Salva, S.; Kanmani, P.; Agüero, G.; Alvarez, S.; Kitazawa, H.; Villena, J. Nasal priming with immunobiotic Lactobacillus rhamnosus modulates inflammation-coagulation interactions and reduces influenza virus-associated pulmonary damage. Inflamm. Res. 2015, 64, 589-602. [CrossRef] [PubMed]

(C) 2018 by the authors. Licensee MDPI, Basel, Switzerland. This article is an open access article distributed under the terms and conditions of the Creative Commons Attribution (CC BY) license (http:/ / creativecommons.org/licenses/by/4.0/). 